\section{International Scientific Journal Theoretical \& Applied Science}

p-ISSN: 2308-4944 (print) e-ISSN: 2409-0085 (online)

Year: $2015 \quad$ Issue: $10 \quad$ Volume: 30

Published: $30.10 .2015 \quad$ http://T-Science.org
Svetlana Valeryevna Fedorova Candidate of Technical Sciences, associate professor Irkutsk national - research technical university, Russia fsta@istu.irk.ru

Inna Aleksandrovna Serebryanik Candidate of Technical Sciences, associate professor Irkutsk National Research Technical University, Russia nasamolet@yandex.ru

SECTION 12. Geology. Anthropology. Archeology.

\title{
THE X-RAY PHASE ANALYSIS OF MIKALEKSOVY COMPOSITION WITH THE NEW BINDING
}

Abstract: The main objective of the X-ray phase analysis of mikaleksovy composition was identification of various phases in mix of mica and glass on the basis of the analysis of a diffraction picture. Definition of substance is carried out to mixes on a set of its interplanar distances and relative intensivnost of the respective lines on.

Key words: X-ray phase analysis, diffraction picture, maca, glass.

Language: Russian

Citation: Fedorova SV, Serebryanik IA (2015) THE X-RAY PHASE ANALYSIS OF MIKALEKSOVY COMPOSITION WITH THE NEW BINDING. ISJ Theoretical \& Applied Science 10 (30): 16-19.

Soi: http://s-o-i.org/1.1/TAS-10-30-5 Doi: crossef http://dx.doi.org/10.15863/TAS.2015.10.30.5

\section{РЕНТГЕНОФАЗОВЫЙ АНАЛИЗ МИКАЛЕКСОВОЙ КОМПОЗИЦИИ С НОВЫМ СВЯЗУЮЩИМ}

Аннотация: Основной задачей рентгенофазового анализа микалексовой композиции являлась идентификация различных фаз в смеси слюды и стекла на основе анализа дифракционной картины. Определение вещества в смеси проводится по набору его межплоскостных расстояний и относительным интенсивностям соответствуюших линий на рентгенограмме.

Ключевые слова: Рентгенофазовый анализ, дифракционная картина, слюда, стекло.

Исследуемыми материалами являются:

а) мелкокристаллическая слюда мусковит,

б) слюда в смеси со стеклом $\mathrm{N}$ в порошке, с соотношением компонентов - $40 \%$ стекла и $60 \%$ слюды,

в) шлифы продольного и перпендикулярного срезов спеченной композиции.

Были отсняты дифрактограммы чистой слюды мусковит и шлифы продольного и перпендикулярного срезов микалекса на основе стекла 203. В качестве компонента, закрепляющего в кювете исследуемые материалы, использовалась борная кислота. Результаты рентгенофазового анализа представлены в графиках (BURASL, BURASLN, BPM, BURAN, BURAM). Анализ фазового состава спеченных образцов, исследованных в продольной и перпендикулярной плоскостях, показали, что во время спекания слюды со стеклом образуются фазы силикатной группы. В спеченной и отпрессованной стекло - слюдяной композиции обнаружены два политипа мусковита $2 \mathrm{M}$ и 3Т. [1, c.81] В перпендикулярном срезе спеченной композиции зарегистрированы: микроклин $\mathrm{K}\left[\mathrm{AlSi}_{3} 0_{8}\right]$ и дистен $\mathrm{Al}_{2} \mathrm{O}_{3} \quad\left[\mathrm{SiO}_{2}\right]$ в продольном срезе обнаружены также микроклин и дистен, кроме того, силлиманит $\mathrm{A}_{2} \mathrm{O}_{3}\left[\mathrm{SiO}_{2}\right]$ и муллит $\mathrm{Al}_{4} \mathrm{Si}_{8}$. Интенсивности пиков новообразованных фаз продольного и перпендикулярного среза шлифов, неодинаковы. Полученные результаты являются экспериментальным доказательством того, что при формировании композиции на межфазовой границе слюда-стекло образуются все четыре вышеназванных силиката. Образование новых фаз связано с особенностью структуры слюды. Разновидности политипии мусковита отличаются межслоевым катионом и заселением элементами тетраэдрических октаэдрических сеток.

Преобладающая ориентировка порошка при подготовке образца к съемке приводит к существенному усилению интенсивности базальных рефлексов. Слюдяные частицы устанавливаются при прессовании 
преимущественно плоскостью спайности в отражающее положение, и вероятность отражения положение и вероятность отражения кристаллографической плоскости общего положения значительно уменьшается, следовательно, уменьшается интенсивность рефлексов общего положения.

Процесс взаимодействия слюды и стекла можно представить следующим образом: после плавления жидкой фазы - стекла происходит сближение и перераспределение зерен слюды. Между двумя, близко расположенными зернами спекаемого вещества, появляется прослойка смачивающей жидкости стекла, приобретающая форму линзы с вогнутым мениском на границе с воздушной средой. Силы поверхностного натяжения вызывают избыточное давление, направленное в сторону центра кривизны мениска. Это давление перемещает жидкость из зоны контакта, за счет чего происходит сближение твердых зерен, сопровождающееся более плотной упаковкой частиц и заполнением пор стеклом. Одновременно протекает процесс растворения твердой фазы слюды в жидком стекле и, по мере ее насыщения, кристаллизация из нее новой фазы. В первую очередь растворение идет в местах контакта, в результате чего происходит дальнейшее сближение кристаллов. Мелкие кристаллы могут полностью раствориться, однако, более крупные растут идет процесс перекристаллизации через расплав.

Заканчивается процесс образования композита рекристаллизации раствора слюды в стекле и прекращением уплотнения. Формируется жесткий каркас. На процесс образования новых фаз оказывает влияние давление, которое в

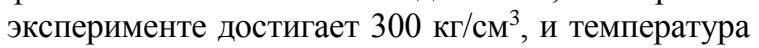

около $750^{\circ} \mathrm{C}$. Приложение давления к нагретому мелкодисперсному стекло-слюдяному брикету приводит к пластической деформации кристаллов слюды и всей композиции. При этом происходит взаимное перераспределение зерен, увеличение количества контактов, заполнение пустот, в результате чего значительно возрастает плотность спеченного материала. [2,с.111-116]

Образование новых фаз можно представить в виде уравнения реакции.

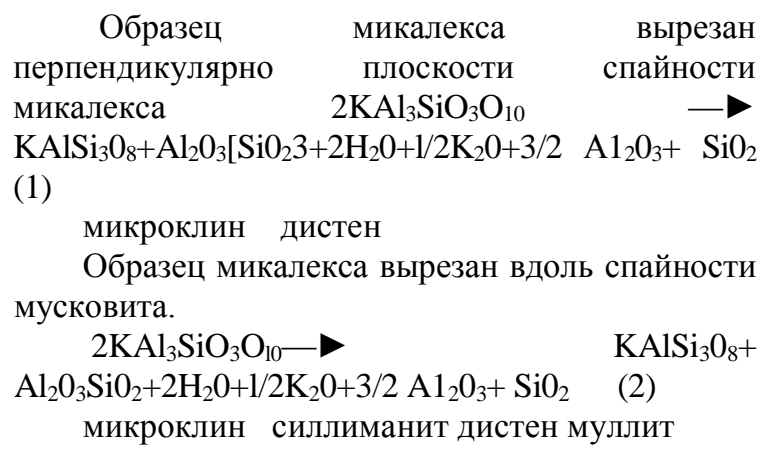

Область изоморфного замещения при зарождении новых фаз необходимо изучить с помощью инфракрасной спектроскопии.

С помощью рентгенофазового анализа в полученной композиции слюда-стекло зарегистрированы образования новых соединений: калиевого шпата, силлиманита, муллита, дистена, также фиксируются два политипа мусковита $2 \mathrm{M} \mid$ и $3 \mathrm{~T}$, что происходит за счет инконгруэнтного плавления. [3, с.175-185]. 


\begin{tabular}{|c|c|c|c|c|c|c|}
\hline Impact Factor: & $\begin{array}{l}\text { ISRA (India) } \\
\text { ISI (Dubai, UAF } \\
\text { GIF (Australia) } \\
\text { JIF }\end{array}$ & $\begin{array}{l}=1.344 \\
=0.829 \\
=0.356 \\
=1.500\end{array}$ & $\begin{array}{l}\text { SIS (USA) } \\
\text { PИHЦ (Russia) } \\
\text { ESJI (KZ) } \\
\text { SJIF (Morocco) }\end{array}$ & $\begin{array}{l}=0.912 \\
=0.179 \\
=1.042 \\
=2.031\end{array}$ & ICV (Poland) & $=6.630$ \\
\hline
\end{tabular}

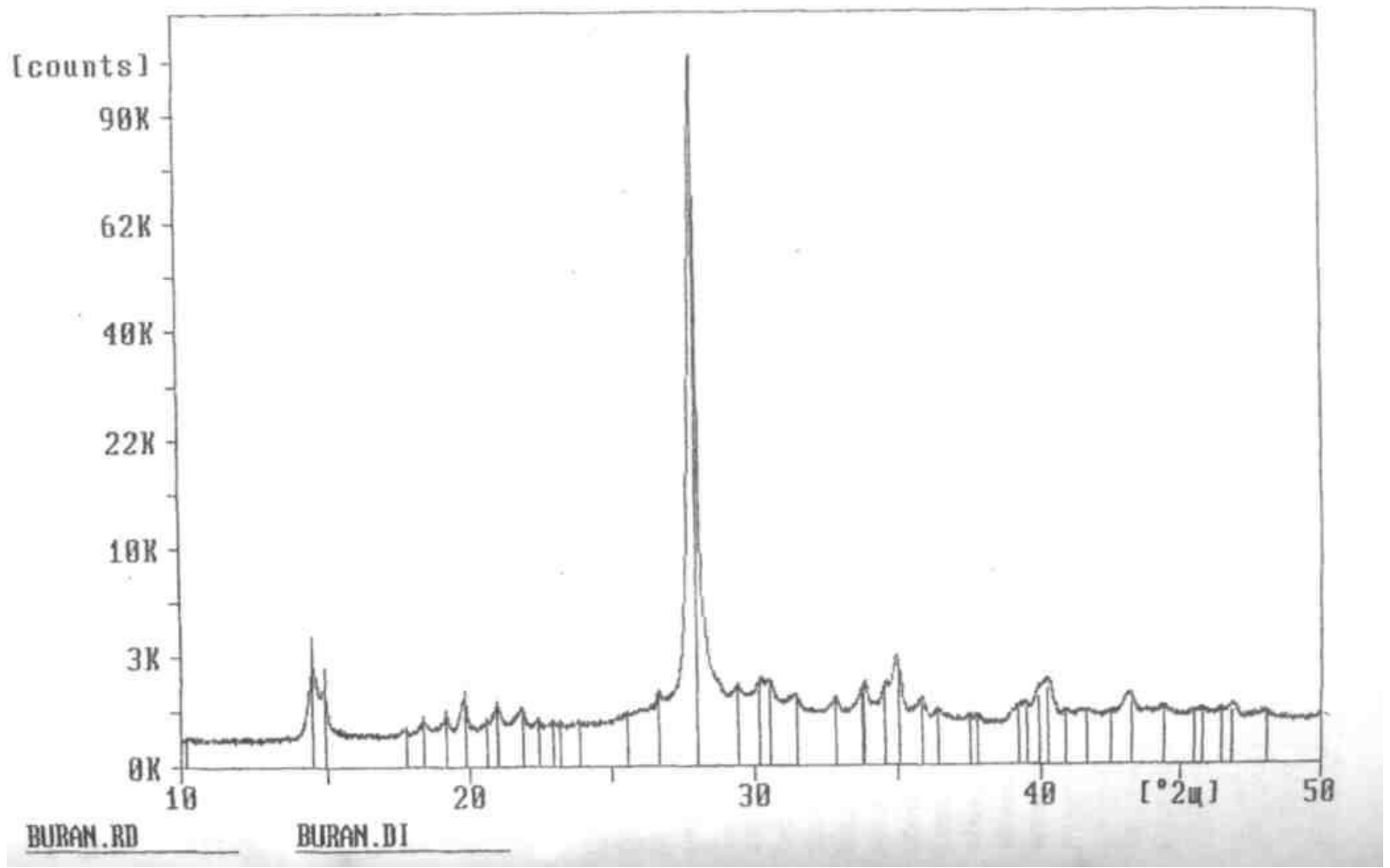

Рисунок 1 - Рентгенограмма композиции BURAN.

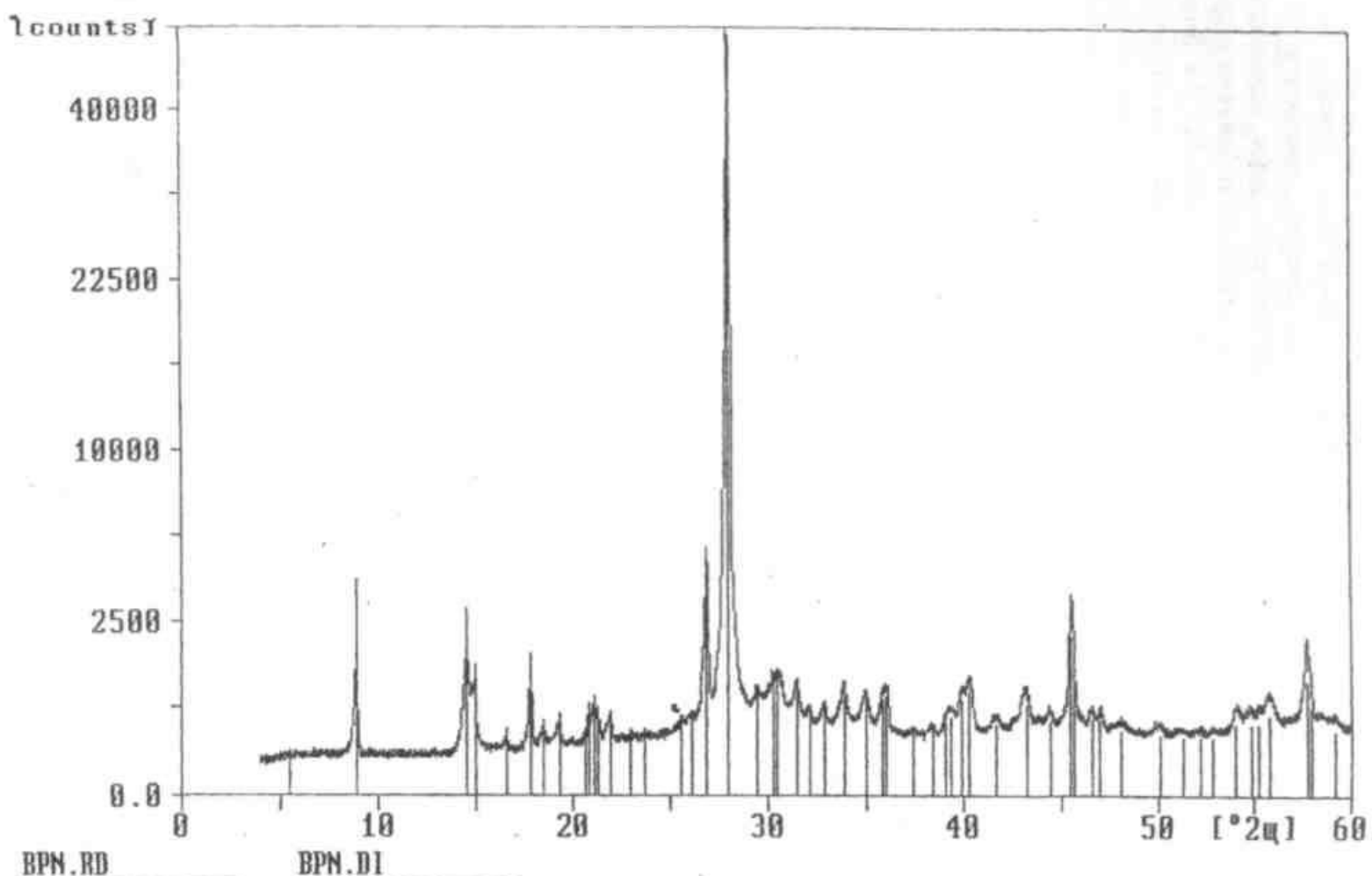

Рисунок 2 - Рентгенограмма композиции BPN.

ISPC Innovations in science, 
В наших исследования рентгенофазовый анализ применялся для установления структурных изменений и минеральной природы новообразования в микалексе в зоне контакта слюды и стекла. Когерентно рассеянные рентгеновские лучи интерферируют между собой, при этом дифракционной решеткой для рентгеновского излучения служит кристаллическая решетка, поскольку межплоскостные расстояния в кристалле сравнимы с длиной волны излучения. Образцы представляли собой плоские прямоугольники горизонтального и вертикального срезов микалекса с размерами $2 * 0,5 * 0,3$ см3 и порошковые смеси.

Для разориентации частиц порошки смешивались с борной кислотой, помещались в металлическую кювету диаметром 20 и глубиной 2 мм. Избыток препарата срезали в одно касание ребром пластины.

\section{References:}

1. Kuznecova GA, Kalihman VA, Mecik MS (1989) Rentgenograficheskoe issledovanie vysokotemperaturnyh prevrashhenij $\mathrm{v}$ sljudah raznogo tipa // Metody difrakcionnyh issledovanij materialov.- Novosibirsk, 1989.pp.81.

2. Kuznecova GA, Kalihman VA, Liopo VA (1979) Rentgenograficheskoe izuchenie strukturnyh prevrashhenij muskovita i flogopita pri nagrevanii do $1500{ }^{\circ} \mathrm{S} / /$ Rentgenografija mineral'nogo syr'ja,- Voronezh, 1979.- pp. 111116.

3. Kataev AA (1989) Osnovnye tetrajedricheskie motivy $\mathrm{v}$ strukturah lentochnyh sloistyh i karkasnyh mineralov iz klassa silikatov // Metody difrakcionnyh issledovanij kristallicheskih materialov.- Novosibirsk: Nauka, Sib. otd-e, 1989.- pp. 158-175.

4. Chilikanova LV, Shishelova TI, Grigor'eva TI, Mecik MS (1986) Rentgenograficheskoe issledovanie flogopitovogo mikaleksa /Rentgenograficheskij analiz rud i mineralov. Moscow, 1986. -pp. 98-101.

5. Shishelova TI, Leonova NV, Drobot NM, Fed'kovich LN (1986) Rentgenograficheskoe izuchenie termicheskogo razlozhenija sljud $\mathrm{v}$ rasplavlennom stekle. Materialy $\mathrm{X}$ Vsesojuznogo soveshhanija po rentgenografii mineral'nogo syr'ja.-Tbilisi,1986.- pp. 218.

6. Sozinova TV, Voronov VK, Drobot NM, Shishelova TI (1988) Fazovye vzaimodejstvija pri poluchenii kompozicionnyh materialov na osnove sljud / U1 Vsesojuznaja konferencija po fizike dijelektrikov: Tez. dokl. konf. Tomsk 2325 nov 1988.-Tomsk,1988.- pp. 107-109.

7. Sozinova TV, Drobot NM, Shishelova TI, Pervushkina JI (1988) Vzaimodejstvie muskovita so steklom pri poluchenii ogneupornogo mikaleksa / Izv. vuzov: Himija i himicheskaja tehnologija.- 1988.-T.31.- № 4.pp. 84-87.

8. Doncova SG, Samojlova OV, Sozinova TV, Shishelova TI (1989) Rentgenograficheskoe i metallograficheskoe izuchenie fazovyh vzadejstvij sljudokompozita i nagrevatelja v SKJeNah / HP Vsesojuznoe soveshhanie po rentgenografii mineral'nogo syr'ja Tez.dokl. k soveshh. - Miass. 10-15 jul 1989. pp. 124.

9. Sozinova TV, Shishelova TI, Drobot NM, Tjurin NG, Bobrova GI (1989) Fazovye vzaimodejstvija sljudy pri poluchenii sljudokompozitov // HP Vsesojuznoe soveshhanie po rentgenografii mineral'nogo syr'ja: Tez. dokl.k soveshh.-Miass,10-15 jul 1989.- pp. 123.

10. (1989) A.S. 1491952 SSSR. Sostav dlja izgotovlenija mikaleksa / Shishelova T.N., Perepelinyj V.A. Drobot N.M., Voronov V.L., Sozinova T.V.-4260555/29-33; Zajavl.4.05.87. Opubl.8.03.89-Bjul. 25.

11. Chilikanova LV, Bajborodin BA, Fedorova SV, Perfil'eva JV (1993) Smachivanie sljud legkoplavkimi steklami. Tezisy nauchnoprakticheskoj konferencii "Razvitie himikometallurgicheskih tehnologij" 27-29 apr Irkutsk.-1993.- pp. 53.

12. Bajborodin BA, Chilikanova LV, Perfil'eva JV, Fedorova SV (1993) Ispol'zovanie othodov mikaleksa v sljudokeramcheskoj promyshlennosti /Tezisy nauchno-prakticheskoj konferencii "Razvitie himiko-metallurgicheskih tehnologij". 27-29 apr, Irkutsk.-1993. - pp. 32. 